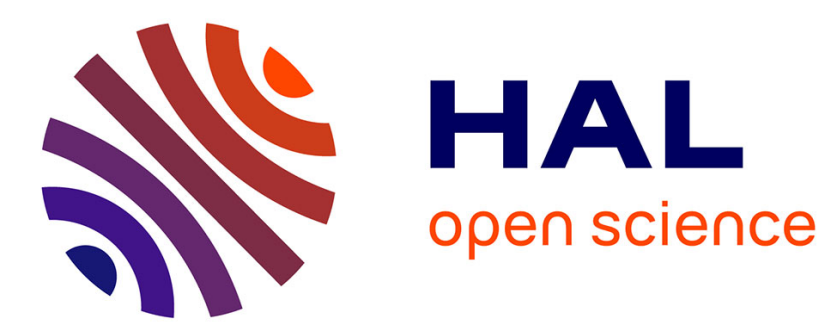

\title{
Ab initio structures and quartic force fields of phosphine oxide and phosphine sulphide
}

Riccardo Tarroni, Manuele Lamarra

\section{To cite this version:}

Riccardo Tarroni, Manuele Lamarra. Ab initio structures and quartic force fields of phosphine oxide and phosphine sulphide. Molecular Physics, 2011, pp.1. 10.1080/00268976.2011.601281 . hal00721228

\section{HAL Id: hal-00721228 \\ https://hal.science/hal-00721228}

Submitted on 27 Jul 2012

HAL is a multi-disciplinary open access archive for the deposit and dissemination of scientific research documents, whether they are published or not. The documents may come from teaching and research institutions in France or abroad, or from public or private research centers.
L'archive ouverte pluridisciplinaire HAL, est destinée au dépôt et à la diffusion de documents scientifiques de niveau recherche, publiés ou non, émanant des établissements d'enseignement et de recherche français ou étrangers, des laboratoires publics ou privés. 


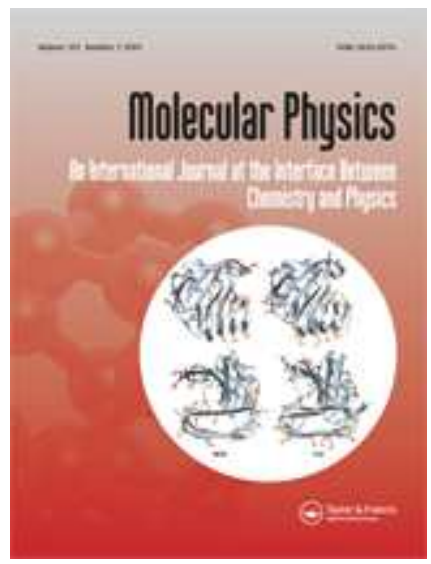

\section{Ab initio structures and quartic force fields of phosphine oxide and phosphine sulphide}

\begin{tabular}{|r|l|}
\hline Journal: & Molecular Physics \\
\hline Manuscript ID: & TMPH-2011-0091.R1 \\
\hline $\begin{array}{r}\text { Manuscript Type: } \\
\text { Author: }\end{array}$ & Special Issue Paper - Dijon HRMS \\
\hline Complete List of Authors: & $\begin{array}{l}\text { Tarroni, Riccardo; Università di Bologna, Chimica Fisica e } \\
\text { Inorganica } \\
\text { Lamarra, Manuele; Università di Bologna }\end{array}$ \\
\hline Keywords: & $\begin{array}{l}\text { ab initio computations, spectroscopic parameters, anharmonic force } \\
\text { field, anharmonic corrections, semi-experimental equilibrium } \\
\text { structure }\end{array}$ \\
\hline \\
\hline $\begin{array}{l}\text { Note: The following files were submitted by the author for peer review, but cannot be converted } \\
\text { to PDF. You must view these files (e.g. movies) online. }\end{array}$ \\
\hline paper_V3.tex \\
\hline
\end{tabular}

\section{SCHOLARONE Manuscripts}




\title{
Ab initio structures and quartic force fields of phosphine oxide and phosphine sulphide
}

\section{Molecular Physics}

\author{
Manuele Lamarra*and Riccardo Tarroni ${ }^{\dagger \ddagger}$
}

Dipartimento di Chimica Fisica ed Inorganica, Università di Bologna, 40136 Bologna, Italy

March 30, 2011

\footnotetext{
${ }^{*}$ Deceased on 17-03-2011

${ }^{\dagger}$ Corresponding author

${ }^{\ddagger}$ E-mail: riccardo.tarroni@unibo.it, Phone: +39-0541-434553, Fax: +39-0541-434534
} 


\begin{abstract}
Phosphine oxide, $\mathrm{OPH}_{3}$, and phosphine sulphide, $\mathrm{SPH}_{3}$ have been studied ab initio using various combinations of theoretical methods (MP2, CCSD, CCSD $(T)$ ) and basis sets (cc$\mathrm{pV}(\mathrm{X}+\mathrm{d}) \mathrm{Z}$, cc-pCVXZ, X=T,Q). For both molecules, high-level ab-initio full-quartic force fields have been calculated, and these have been used to predict the most important spectroscopic constants for several isotopologues. For $\mathrm{OPH}_{3}$, the semi-experimental equilibrium geometry and harmonic frequencies have been determined, by combining the theoretically calculated anharmonic corrections to the experimentally determined ground-state rotational constants and vibrational fundamentals. It is proved that, after applying anharmonic corrections, the unusually large disagreement between the experimental geometry and any high-level theoretical approach disappears.
\end{abstract}

Keywords: ab initio computations, spectroscopic parameters, anharmonic force field, anharmonic corrections, semi-experimental equilibrium structure, 


\section{Introduction}

Phosphine oxide, $\mathrm{OPH}_{3}$ and phosphine sulphide, $\mathrm{SPH}_{3}$, together with their tautomers $\mathrm{HOPH}_{2}$, $\mathrm{HSPH}_{2}$ and halogen derivatives have been extensively studied in several theoretical papers [1-17] These studies were mainly focused on the molecular structure and the nature of the P-X $(X=O, S)$ bond $[1,2,4,10,13,15]$, on the tautomerization energetics and reaction paths $[1,9,14,15,17]$ and on vibrational spectra $[1,3,5-8]$

Comparatively, much less experimental work has been done. To date, only the Argon matrix infrared spectrum of $\mathrm{OPH}_{3}$ has been observed [18], while the identification of $\mathrm{SPH}_{3}$ from a similar experiment [19] has failed. In the gas phase, only the microwave spectrum of $\mathrm{OPH}_{3}$ has been detected [20], leading to the determination of its $r_{0}$ molecular structure.

Our attention to the title molecules was drawn by the striking discrepancy between the experimental geometry of $\mathrm{OPH}_{3}$, as deduced from its rotational spectrum [20] and any of the previous ab initio calculations, even those carried out at the Coupled Cluster level of theory [15]. Indeed Coupled Cluster methods [21], in particular those including perturbative treatment of triple excitations $[\mathrm{CCSD}(\mathrm{T})][22]$, are nowadays acknowledged to be the most effective compromise between accuracy and computational effort, for the calculation of structures and force fields of closed-shell medium-sized molecules in their ground state [23, 24]. Differences between experimental and calculated geometries are usually within 0.1-0.3 pm for bond lengths and less than 0.5 degrees for bond angles [25]. Even if comparisons are made between calculated $r_{e}$ and experimental $r_{0}$ geometries, for non-flexible molecules the differences often remain within the above ranges.

It appears then noteworthy a difference of $3.7 \mathrm{pm}$ and 2.6 degrees between the calculated [15] and the experimental [20] $\mathrm{PH}$ bond length and $\mathrm{OPH}$ bond angle of $\mathrm{OPH}_{3}$, respectively. Similar unrealistic deviations have been reported also for the $\mathrm{OPH}_{2}$ radical $[26,27]$. As pointed out in Ref.[15], the differences may be primarily attributed to the vibrational effects on the experimental geometry. These anharmonic corrections have never been considered in any of the previous theoretical studies, but they appear to be mandatory to make a direct comparison with experiment. Anharmonic effects must also be taken into account to quantitatively reproduce the observed vibrational frequencies [18], inasmuch the latest ab initio calculations published [7], dating back to our knowledge almost twenty years ago, show deviations as large as $170 \mathrm{~cm}^{-1}$ from the experiment.

In this paper we will then calculate for the first time the full quartic force field for $\mathrm{OPH}_{3}$, using state-of-the-art ab initio quantum chemical methods, in order to achieve a complete agreement with all the experimentally known data. The study has been extended, at the same level of theory, also to $\mathrm{SPH}_{3}$, with the aim of providing information useful for the spectroscopic identification of this molecule. 


\section{Computational methodologies}

All the ab-initio calculations have been performed with the ACES II suite of quantum chemistry programs, Mainz-Austin-Budapest version [28]. The ground state equilibrium geometry and harmonic frequencies have been calculated by means of different combinations of theoretical methods and basis sets. The methods we used are the second order Møller-Plesset perturbation theory (MP2)[29], the Coupled Cluster with Single and Double excitations (CCSD) [30] and the Coupled Cluster with Single and Double excitations with triples treated perturbatively $[\operatorname{CCSD}(\mathrm{T})][22]$. The bases, of triple and quadruple $\zeta$ quality, were chosen among the family of Dunning's correlation consistent sets. In particular we used the cc-pV(T+d)Z, cc-pV $(\mathrm{Q}+\mathrm{d}) \mathrm{Z}[31]$ bases, with only valence electrons correlated, and the cc-pCVTZ, cc-pCVQZ [32] bases, with all electrons correlated.

These combinations of methods and bases were chosen since they are most commonly used in similar studies [23]. For each combination, the harmonic frequencies and the dipole moment have been calculated at the corresponding equilibrium geometry.

The CCSD(T)/cc-pCVQZ geometry was chosen as reference geometry for the calculation of the full quartic force field. The harmonic part of the force field was obtained analytically at the same level of the geometry optimization, while the complete set of cubic and quartic force constants, in Cartesian coordinates, were obtained from the finite differences of the analytical hessians evaluated at a lower level of theory (MP2/cc-pCVTZ). Such a hybrid approach relies on the smaller effects of basis set and electron correlation with increasing the order of the force fields [33]. The Cartesian geometries used in the finite differences procedure have been generated starting from the $\operatorname{CCSD}(\mathrm{T})$ /cc-pCVQZ equilibrium geometry, by increasing and decreasing the Cartesian coordinates with a step-size of 0.006 bohr, without taking into account symmetry relationships. 30 singly displaced and 210 doubly displaced structures are needed for a five atom molecule. The numerical stability of the procedure against the step size was checked by comparing the values of the $F_{i j k l}$ and $F_{k l i j}$ quartic force field elements in Cartesian coordinates. The maximum absolute differences was $0.03 \mathrm{aJ} \AA^{-n} \mathrm{rad}^{-m}(m+n=4)$.

The transformation of force constants from cartesian to normal coordinates and the computation of the spectroscopic constants [34, 35] have been performed with the SPECTRO program[36], while the transformation from cartesian to internal coordinates was performed with the INTDER program $[33,37,38]$. In the transformation of the Cartesian force constants to internal coordinates, the small gradient term resulting from the choice of a non-stationary reference geometry was neglected, since the CCSD(T)/cc-pCVQZ and MP2/cc-pCVTZ geometries are almost coincident, differing at most $0.6 \mathrm{pm}$ for the bond lengths and 0.3 degree for the angles. 


\section{Discussion}

\subsection{Comparison of the ab initio methods}

In Table 1 and 2 we compare the geometries, the dipole moments and the harmonic frequencies of $\mathrm{OPH}_{3}$ and $\mathrm{SPH}_{3}$. The comparison is made, for $\mathrm{OPH}_{3}$, against semi-experimental equilibrium structures and harmonic frequencies, obtained from experimental $B_{0}[20]$ and anharmonic frequencies $\nu$ [18] after applying the theoretically calculated anharmonic corrections (see below).

We can see that in general the calculated $r_{e}(\mathrm{PO})$ overestimate the semi-empirical PO bond length, with larger deviations when only valence electrons are correlated. The smallest deviation $(+0.04 \mathrm{pm})$ is found at the $\operatorname{CCSD}(\mathrm{T}) / \mathrm{cc}-\mathrm{pCVQZ}$ level, indicating that an high level of correlation treatment, including core correlation, is needed to accurately describe the PO bond.

On the other hand, the calculated $r_{e}(\mathrm{PH})$ are much less sensitive to the combination of method and basis, with both positive and negative deviations with respect to the semi-experimental value. The largest deviation is observed for the MP2/cc-pCVQZ approach, but it is less than $1 \mathrm{pm}$. Also $\mathrm{OPH}$ angle show little dependence on the method/basis combination, and they always overestimate the corresponding semi-empirical value by less than 0.5 degrees.

From the comparisons described above, it emerges that the best agreement with the semiexperimental equilibrium geometry is obtained at the $\operatorname{CCSD}(\mathrm{T}) / \mathrm{cc}-\mathrm{pCVQZ}$ level. This "a posteriori" check validates its use as reference geometry for the calculation of the full quartic anharmonic force field and consequently of the anharmonic corrections which in turn are used to obtain the semi-experimental geometry itself, as described in the next section.

For what harmonic frequencies are concerned, the performance of the various approaches is ranked by calculating the root mean square deviation (RMSD) from the semi-experimental harmonic frequencies. These have been estimated by applying anharmonic corrections (see next section) to the observed fundamental frequencies obtained from rare-gas trapping experiments [18], as no gas-phase data was available at the time of writing. The largest RMSD $\left(33.5 \mathrm{~cm}^{-1}\right)$ is obtained for MP2/cc-pCVQZ and the smallest $\left(10.7 \mathrm{~cm}^{-1}\right)$ for CCSD(T)/cc-pCVQZ. The relatively high RMSD, even for the best theoretical treatment, probably reflects some frequency shifts of the fundamentals due to the solid state environment. It is then unlikely that higher levels of theory could markedly improve the RMSD with respect to these experimental data. The accuracy of the semi-experimental harmonic frequencies presented here is then affected by the unavoidable shifts due to the trapping matrix, which can be safely assumed to be about $1 \%$ of the frequency values $[39]$

For $\mathrm{SPH}_{3}$ the comparison is made against the values obtained from the $\mathrm{CCSD}(\mathrm{T}) / \mathrm{cc}-\mathrm{pCVQZ}$ calculation, since experimental data are not currently available and this latter method has proved 
to perform very well for $\mathrm{OPH}_{3}$. Most methods tend to overestimate the SP bond length, with differences ranging from $-2.54 \mathrm{pm}(\mathrm{QCISD} / 6-311++\mathrm{G}(\mathrm{d}, \mathrm{p})[16,17]$ to $+0.99 \mathrm{pm}$ (MP2/cc-pCVQZ). As for $\mathrm{OPH}_{3}$, the $\mathrm{PH}$ bond length and $\mathrm{SPH}$ bond angles are comparatively more stable, with a largest deviation of $+0.47 \mathrm{pm}$ (MP2/cc-pCVTZ) and 0.21 degrees $(\mathrm{CCSD}(\mathrm{T}) / \mathrm{cc}-\mathrm{pV}(\mathrm{T}+\mathrm{d}) \mathrm{Z})$, respectively.

For what frequencies are concerned, the QCISD/6-311++G(d,p) $[16,17]$ is particularly unsatisfactory, with a RMSD of $36.0 \mathrm{~cm}^{-1}$ and a largest deviation of $+61.6 \mathrm{~cm}^{-1}$ for $\omega_{2}$. In general, all MP2 approaches provide a poor description of the harmonic frequencies, with values always overestimated with respect to the CCSD(T)/cc-pCVQZ values and RMSD ranging from $24.3 \mathrm{~cm}^{-1}$ $(\mathrm{MP} 2 / \mathrm{cc}-\mathrm{pV}(\mathrm{T}+\mathrm{d}) \mathrm{Z})$ to $30.6 \mathrm{~cm}^{-1}(\mathrm{MP} 2 / \mathrm{cc}-\mathrm{pCVQZ})$ and a maximum deviation of $+47.3 \mathrm{~cm}^{-1}$ for $\omega_{4}(\mathrm{MP} 2 / \mathrm{cc}-\mathrm{pCVQZ})$.

\subsection{Anharmonic force fields}

The quadratic, cubic and quartic force fields transformation from cartesian to symmetry coordinates was done by means of the INTDER program $[33,37,38]$. The definition of the symmetry coordinates is reported in Table 3. These are the same as in Ref.[5], but are reported also here for completeness. The definition of the internal coordinates is also shown in Figure 1.

The harmonic, cubic and quartic force field of $\mathrm{OPH}_{3}$ and $\mathrm{SPH}_{3}$ in symmetry coordinates are reported in Tables 4-6. These have been used to calculate fundamental frequencies, anharmonicity constants, rotational and rotation-vibration constants for most common isotopologues, in order to assist future identification and analysis of gas-phase spectra. These values are reported in Table 7 , together with the latest computed and experimental values.

The application of the vibration-rotation second order perturbation theory equations $[34,35]$ needed in this step, has been accomplished by means of the SPECTRO [36] code. Fermi resonances have been taken into account following Ref.[35], by removing the divergent terms from the expression of the anharmonicity constants and explicitly diagonalizing the $2 \times 2$ matrix involving the resonant states. The effect of Coriolis resonances has been accounted by properly modifying the analytical expression of the vibration-rotation constants [34].

The listed spectroscopic constants have been finally used to calculate the anharmonic contribution to fundamental frequencies and to rotational constants, in order to estimate semi-experimental harmonic frequencies and equilibrium rotational constants. The semi-experimental harmonic frequencies $\omega_{i}^{s e}$ have been obtained from the experimental fundamentals $\nu_{i}^{e}$ using the following equations, obtained from the vibrational term value expression for symmetric tops (see e.g. [34]):

$$
\omega_{i}^{s e}=\nu_{i}^{e}-2 x_{i i}-\frac{1}{2} \sum_{s \neq i} x_{s i}-\sum_{t} x_{t i} \quad \text { non }- \text { degenerate modes }
$$




$$
\omega_{i}^{s e}=\nu_{i}^{e}-3 x_{i i}-g_{i i}-\frac{1}{2} \sum_{s} x_{s i}-\sum_{t \neq i} x_{t i} \quad \text { degenerate modes }
$$

where $s$ denotes a non-degenerate and and $t$ a degenerate mode. The semi-experimental harmonic frequencies for $\mathrm{OPH}_{3}$ are reported in Table 1 .

Semi experimental equilibrium rotational constants $B_{e}^{s e}$ for $\mathrm{OPH}_{3}$ are obtained from the experimental $B_{0}^{e}[20]$ by applying the following expression for all available isotopologues

$$
B_{e}^{s e}=B_{0}^{e}+\sum_{i} \frac{d_{i}}{2} \alpha_{i}^{B}
$$

where $d_{i}$ is 1 for non-degenerate and 2 for degenerate modes. The vibrational corrections to the ground state rotational constants turned out to be 107.586, 83.738 and $97.157 \mathrm{MHz}$, for the ${ }^{16} \mathrm{OPH}_{3},{ }^{16} \mathrm{OPD}_{3}$ and ${ }^{18} \mathrm{OPH}_{3}$ isotopologues, respectively. By applying these corrections to the experimental $B_{0}^{e}$ values [20], one obtains the semi-experimental $B_{e}^{s e}: 17534.2077,14683.5899$ and 16355.8216 MHz. Finally, by fitting the symmetric top geometrical parameters to these values, by means of the STRFIT program [40], we obtained the best estimate of the experimental $r_{e}$ structure of $\mathrm{OPH}_{3}: r_{e}(\mathrm{PO})=1.4703 \AA, r_{e}(\mathrm{PH})=1.4043 \AA$ and $\angle \mathrm{HPO}=116.72^{\circ}$, which is also reported in Table 1. As pointed out in the previous subsection, the CCSD $(\mathrm{T}) /$ cc-pCVQZ geometry is almost coincident with the semi-experimental one, hence settling this molecule for the apparent disagreement between theory and experiment.

\section{Conclusions}

Phospine oxide and phosphine sulphide have been studied ab-initio using different combinations of theoretical methods and basis sets. Among the various possibilities, we have chosen those most widely adopted for spectroscopic studies [23], that is MP2 (bases cc-pV $(\mathrm{T}+\mathrm{d}) \mathrm{Z}$, cc-pV( $\mathrm{Q}+\mathrm{d}) \mathrm{Z}$, cc-pCVTZ, cc-pCVQZ), CCSD (bases cc-pV(T+d)Z, cc-pV(Q+d)Z), and CCSD(T) (bases cc$\mathrm{pV}(\mathrm{T}+\mathrm{d}) \mathrm{Z}$, cc-pV $(\mathrm{Q}+\mathrm{d}) \mathrm{Z}$, cc-pCVTZ, cc-pCVQZ). For phosphine oxide, an almost perfect agreement with respect to the semi-experimental results is obtained only by taking into account core correlation. The same agreement is guessed also for phosphine sulphide, which unfortunately is completely lacking of experimental data.

For both molecules, high-level ab-initio full-quartic force fields have been also calculated. These have been used to both predict the most important spectroscopic constants for several isotopologues and to estimate, for $\mathrm{OPH}_{3}$, the anharmonic corrections needed to obtain the semi-experimental equilibrium geometry and harmonic frequencies. The large disagreement between the experimental geometry and any high-level theoretical approach, as pointed out by some authors [15, 20], is then completely eliminated. Work is in progress to solve an analogous problem observed for the $\mathrm{OPH}_{2}$ 
radical $[26,27]$.

\section{Acknowledgments}

This work was supported by the University of Bologna, Polo di Rimini. 


\section{References}

[1] M. W. Schmidt, S. Yabushita, and M. S. Gordon, J. Phys. Chem. 88, 382 (1984).

[2] M. W. Schmidt and M. S. Gordon, J. Am. Chem. Soc. 107, 1922 (1985).

[3] W. B. Person, J. S. Kwiatkowski, and R. J. Bartlett, J. Mol. Struct. 157, 237 (1987).

[4] J. A. Boatz, M. W. Schmidt, and M. S. Gordon, J. Phys. Chem. 91, 1743 (1987).

[5] W. Schneider, W. Thiel and A. Komornicki, J. Phys. Chem. 92, 5611 (1988).

[6] J. Breidung, W. Schneider, W. Thiel, and H. F. Schaefer III, J. Mol. Spectr. 140, 226 (1990).

[7] J. Kwiatkowsky and J. Leszczynski, J. Phys. Chem. 96, 6636 (1992).

[8] J. S. Kwiatkowski and J. Leszczyński, J. Mol. Struct. (Theochem) 257, 85 (1992).

[9] J. S. Kwiatkowski and J. Leszczyński, Mol. Phys. 76, 475 (1992).

[10] C. Yang, E. Goldstein, S. Breffle and S. Jin, J. Mol. Struct. (Theochem) 259, 345 (1992).

[11] D. G. Gilheany, Chem. Rev. 94, 1339 (1994).

[12] E. L. Stewart, N. Nevins, N. L. Allinger and J. P. Bowen, J. Org. Chem. 62, 5198 (1997).

[13] J. A. Dobado, H. Martinez-Garcia, J. Molina, M. R. Sundberg, J. Am. Chem. Soc. 120, 8461 (1998).

[14] D. B. Chesnut, Heteroat. Chem. 11, 73 (2000).

[15] S. S. Wesolowski, N. R. Brinkmann, E. F. Valeev, H. F. Schaefer III, M. R. Repasky, and W. L. Jorgensen, J. Chem. Phys. 116, 112 (2002).

[16] W. N. Wang, W. L. Wang, Q. Luo and Q. S. Li , Chem. Phys. Lett. 415, 370 (2005).

[17] R. B. Viana and A. S. Pimentel, J. Chem. Phys. 127, 204206 (2007).

[18] R. Withnall and L. Andrews, J. Phys. Chem. 91, 784 (1987).

[19] Z. Mielke, L. Andrews, J. Phys. Chem. 97, 4313 (1993).

[20] I. K. Ahmad, H. Ozeki, and S. Saito, J. Chem. Phys. 110, 912 (1999).

[21] R. J. Bartlett and M. Musial, Rev. Mod. Phys. 79, 291 (2007). 
[22] K. Raghavachari, G. W. Trucks, J. A. Pople and M. Head-Gordon, Chem. Phys. Lett. 157, 479 (1989).

[23] J. Demaison, Mol. Phys. 105, 3109 (2007).

[24] C. Puzzarini and V. Barone, Int. J. Quantum Chem. 110, 637 (2009).

[25] T. Helgaker, J. Gauss, P. Jørgensen, J. Olsen, J. Chem. Phys. 106, 6430 (1997).

[26] T. Hirao, S. Saito, H. Ozeki, J. Chem. Phys. 105, 3450 (1996).

[27] S.S. Wesolowski, E. M. Johnson, M. L. Leininger, D. Crawford and H. F. Schaefer III, J. Chem. Phys. 109, 2694 (1998).

[28] J. F. Stanton, J. Gauss, J. D. Watts, P. G. Szalay, R. J. Bartlett, with contributions from A. A. Auer, D. B. Bernholdt, O. Christiansen, M. E. Harding, M. Heckert, O. Heun, C. Huber, D. Jonsson, J. Jusélius, W. J. Lauderdale, T. Metzroth, C. Michauk, V. O’Neill, D. R. Price, K. Ruud, F. Schiffmann, M. E. Varner, J. Vázquez, and the integral packages MOLECULE (J. Almlöf, P. R. Taylor), PROPS (P. R.Taylor), and ABACUS (T. Helgaker, H. J. Aa. Jensen, P. Jørgensen, J. Olsen). For the current version, see http://www.aces2.de..

[29] C. Møller and M. S. Plesset, Phys. Rev. 46, 618 (1934).

[30] G. D. Purvis III and R. J. Bartlett, J. Chem. Phys. 76, 1910 (1982).

[31] (a) T. H. Dunning, Jr., J. Chem. Phys. 90, 1007 (1989); (b) D. E. Woon, T. H. Dunning, Jr., J. Chem. Phys. 103, 4572 (1995); (c) T. H. Dunning, Jr., K. A. Peterson, K. A. Wilson, J. Chem. Phys. 114, 9244 (2001).

[32] K. A. Peterson and T. H. Dunning, Jr., J. Chem. Phys. 117, 10548 (2002).

[33] W. D. Allen and A.G. Csaszar, J. Chem. Phys. 98, 2983 (1993).

[34] D. Papousěk, M. R. Aliev, Molecular vibrational spectra (Elsevier, Amsterdam, 1982).

[35] S. Califano, Vibrational States, (Wiley, London, 1976).

[36] J. F. Gaw, A. Willetts, W. H. Green, N. C. Handy, SPECTRO - a program for derivation of spectroscopic constants from provided quartic force fields and cubic dipole fields", in J. M. Bowman, Ed., Advances in Molecular Vibrations and Collision Dynamics, JAI Press, Greenwich, 1991. 
[37] INTDER2000 is a general program developed by W.D. Allen and co-workers which performs various vibrational analyses and higher order nonlinear transformations among force field representations.

[38] W. D. Allen, A. G. Csaszar, V. Szalay and I. M. Mills, Mol. Phys. 89, 1213 (1996).

[39] M. E. Jacox, Chem. Soc. Rev. 31, 108 (2002).

[40] Z. Kisiel, J. Mol. Spectrosc. 218, 58 (2003). 


\section{Figure captions}

Figure 1.

Internal coordinates used for the definition of the symmetry coordinates of $\mathrm{OPH}_{3}$ and $\mathrm{SPH}_{3}$ 
Table 1: Computed equilibrium geometries, dipole moments and harmonic vibrational frequencies of $\mathrm{OPH}_{3}$. Bond lengths in Angstrom, bond angles in degrees, dipole moments in Debye and vibrational frequencies in $\mathrm{cm}^{-1}$

\begin{tabular}{|c|c|c|c|c|c|c|c|c|c|c|c|}
\hline Method & $r_{e}(\mathrm{PO})$ & $r_{e}(\mathrm{PH})$ & $\angle \mathrm{OPH}$ & $\mu_{e}$ & $\omega_{1}$ & $\omega_{2}$ & $\omega_{3}$ & $\omega_{4}$ & $\omega_{5}$ & $\omega_{6}$ & RMSD \\
\hline $\mathrm{MP} 2 / 6-311 \mathrm{G}^{* * a}$ & 1.4855 & 1.4061 & 117.68 & 3.473 & 2531 & 1327 & 1203 & 2505 & 1181 & 893 & 47.1 \\
\hline $\mathrm{MP} 2 / \mathrm{cc}-\mathrm{pV}(\mathrm{T}+\mathrm{d}) \mathrm{Z}^{b}$ & 1.4785 & 1.4039 & 117.18 & 3.502 & 2503.6 & 1299.2 & 1182.5 & 2488.1 & 1165.6 & 867.3 & 27.2 \\
\hline $\mathrm{MP} 2 / \mathrm{cc}-\mathrm{pV}(\mathrm{Q}+\mathrm{d}) \mathrm{Z}^{b}$ & 1.4781 & 1.4027 & 116.86 & 3.628 & 251 & 1283.8 & 0 & 2498.0 & 3 & 863 & 27.9 \\
\hline MP2/cc-pCVTZ ${ }^{c}$ & 1.4767 & 1.4014 & 117.16 & 3.516 & 2513.0 & 1300.3 & 1182.9 & 2499.6 & 1167.2 & 867.3 & 33.2 \\
\hline MP2/cc-pCVQZ ${ }^{c}$ & 1.4733 & 1.3989 & 116.87 & 3.627 & 2516.9 & 1288.6 & 1177.3 & 2505.5 & 1164.2 & 866.7 & 33.5 \\
\hline $\mathrm{CCSD} / \mathrm{cc}-\mathrm{pV}(\mathrm{T}+\mathrm{d}) \mathrm{Z}^{b}$ & 1.4707 & 1.4058 & 117.04 & 3.611 & 2480.6 & 1307.5 & 1189.0 & 2463.1 & 1160.6 & 872.3 & 23.2 \\
\hline $\mathrm{CCSD} / \mathrm{cc}-\mathrm{pV}(\mathrm{Q}+\mathrm{d}) \mathrm{Z}^{b}$ & 1.4688 & 1.4046 & 116.75 & 3.726 & 2490.2 & 1298.1 & 1181.4 & 2475.1 & 1155.9 & 870.8 & 20.0 \\
\hline $\operatorname{CCSD}(\mathrm{T}) / \mathrm{cc}-\mathrm{pV}(\mathrm{T}+\mathrm{d}) \mathrm{Z}^{b}$ & 1.4767 & 1.4085 & 117.17 & 3.512 & 2455.2 & 1289.4 & 1171.9 & 2438.4 & 1147.7 & 858.5 & 20.9 \\
\hline $\operatorname{CCSD}(\mathrm{T}) / \mathrm{cc}-\mathrm{pV}(\mathrm{Q}+\mathrm{d}) \mathrm{Z}^{b}$ & 1.4754 & 1.4074 & 116.86 & 3.638 & 2464.6 & 1277.1 & 1163.5 & 2450.6 & 1142.5 & 856.0 & 11.1 \\
\hline $\operatorname{CCSD}(\mathrm{T}) / \mathrm{cc}-\mathrm{pCVTZ}{ }^{c}$ & 1.4749 & 1.4064 & 117.15 & 3.523 & 2463.9 & 1292.0 & 1173.3 & 2448.7 & 1149.8 & 859.3 & 16.9 \\
\hline $\operatorname{CCSD}(\mathrm{T}) /$ cc-pCVQZ $^{c}$ & 1.4707 & 1.4040 & 116.88 & 3.633 & 2469.8 & 1283.4 & 1168.1 & 2456.6 & 1145.9 & 860.0 & 10.7 \\
\hline Experimental $^{d, e}$ & 1.4703 & 1.4043 & 116.72 & & 2472.4 & 1261.1 & 1164.9 & 2475.1 & 1140.6 & 864.3 & - \\
\hline
\end{tabular}

${ }^{a}$ From Ref.[7]. To facilitate the comparison with the present data, the empirical scaling factor of 0.943 has been removed. A recent high level structure calculation $[\mathrm{CCSD}(\mathrm{T}) / \mathrm{cc}-\mathrm{pVQZ}]$ is reported also in ref [15]

${ }^{b}$ Only valence electrons correlated

${ }^{c}$ All electrons correlated

${ }^{d}$ Semi-experimental $r_{e}$ structure obtained from the experimental $B_{0}$ of Ref.[20], corrected by the anharmonic contribution (see text).

${ }^{e}$ Semi-experimental harmonic frequencies obtained from the fundamentals of Ref.[18], corrected by the anharmonic contribution (see text) 
Table 2: Computed equilibrium geometries, dipole moments and harmonic vibrational frequencies of $\mathrm{SPH}_{3}$. Bond lengths in angstrom, bond angles in degrees, dipole moments in debye and vibrational frequencies in $\mathrm{cm}^{-1}$

\begin{tabular}{|c|c|c|c|c|c|c|c|c|c|c|c|}
\hline Method & $r_{e}(\mathrm{PS})$ & $r_{e}(\mathrm{PH})$ & $\angle \mathrm{SPH}$ & $\mu_{e}$ & $\omega_{1}$ & $\omega_{2}$ & $\omega_{3}$ & $\omega_{4}$ & $\omega_{5}$ & $\omega_{6}$ & RMSD \\
\hline QCISD $/ 6-311++\mathrm{G}(\mathrm{d}, \mathrm{p})^{a}$ & 1.9507 & 1.4053 & 117.55 & - & 2503 & 1205 & 641 & 2482 & 1129 & 742 & 36.0 \\
\hline $\mathrm{MP} 2 / \mathrm{cc}-\mathrm{pV}(\mathrm{T}+\mathrm{d}) \mathrm{Z}^{b}$ & 1.9258 & 1.4025 & 117.79 & 3.569 & 2501.1 & 1165.0 & 749.1 & 2488.6 & 1153.0 & 703.6 & 24.3 \\
\hline $\mathrm{MP} 2 / \mathrm{cc}-\mathrm{pV}(\mathrm{Q}+\mathrm{d}) \mathrm{Z}^{b}$ & 1.9225 & 1.4017 & 117.58 & 3.583 & 2507.6 & 1157.0 & 748.9 & 2496.3 & 1148.3 & 706.4 & 26.5 \\
\hline MP2/cc-pCVTZ ${ }^{c}$ & 1.9220 & 1.4002 & 117.81 & 3.567 & 2509.9 & 1165.5 & 703.6 & 2499.3 & 1154.6 & 748.3 & 29.1 \\
\hline $\mathrm{MP} 2 / \mathrm{cc}^{\mathrm{pCVQZ}}{ }^{\mathrm{c}}$ & 1.9154 & 1.3981 & 117.63 & 3.565 & 2513.2 & 1159.7 & 708.8 & 2502.8 & 1151.4 & 750.7 & 30.6 \\
\hline $\mathrm{CCSD} / \mathrm{cc}-\mathrm{pV}(\mathrm{T}+\mathrm{d}) \mathrm{Z}^{b}$ & 1.9336 & 1.4042 & 117.67 & 3.702 & 2479.6 & 1159.1 & 740.5 & 2464.8 & 1147.9 & 680.4 & 11.1 \\
\hline $\mathrm{CCSD} / \mathrm{cc}-\mathrm{pV}(\mathrm{Q}+\mathrm{d}) \mathrm{Z}^{b}$ & 1.9286 & 1.4032 & 117.44 & 3.737 & 2489.7 & 1151.8 & 743.4 & 2476.2 & 1143.7 & 686.2 & 13.8 \\
\hline $\operatorname{CCSD}(\mathrm{T}) / \mathrm{cc}-\mathrm{pV}(\mathrm{T}+\mathrm{d}) \mathrm{Z}^{b}$ & 1.9363 & 1.4070 & 117.83 & 3.582 & 2453.7 & 1148.8 & 731.2 & 2438.6 & 1134.8 & 677.8 & 10.1 \\
\hline $\operatorname{CCSD}(\mathrm{T}) / \mathrm{cc}-\mathrm{pV}(\mathrm{Q}+\mathrm{d}) \mathrm{Z}^{b}$ & 1.9317 & 1.4061 & 117.59 & 3.628 & 2463.3 & 1139.6 & 732.8 & 2449.9 & 1129.5 & 682.7 & 4.1 \\
\hline $\operatorname{CCSD}(\mathrm{T}) / \mathrm{cc}-\mathrm{pCVTZ}{ }^{c}$ & 1.9330 & 1.4048 & 117.83 & 3.584 & 2462.4 & 1150.2 & 678.5 & 2448.9 & 1136.9 & 731.4 & 6.0 \\
\hline $\operatorname{CCSD}(\mathrm{T}) / \mathrm{cc}-\mathrm{pCVQZ}{ }^{c}$ & 1.9253 & 1.4028 & 117.62 & 3.615 & 2468.2 & 1143.4 & 686.0 & 2455.5 & 1133.0 & 735.6 & - \\
\hline
\end{tabular}

${ }^{a}$ Ref.[16, 17], EPAPS document No. E-JCPSA6-127-302742

${ }^{b}$ Only valence electrons correlated

${ }^{c}$ All electrons correlated 
Table 3: Definition of symmetry coordinates for $\mathrm{OPH}_{3}$ and $\mathrm{SPH}_{3}$ according to ref.[5]

\begin{tabular}{ll}
\hline Coordinate & Definition $^{a}$ \\
\hline$S_{1}$ & $\left(\Delta r_{1}+\Delta r_{2}+\Delta r_{3}\right) / \sqrt{3}$ \\
$S_{2}$ & $\left(K \Delta \alpha_{1}+K \Delta \alpha_{2}+K \Delta \alpha_{3}-\Delta \beta_{1}-\Delta \beta_{2}-\Delta \beta_{3}\right) / \sqrt{3+K^{2}}$ \\
$S_{3}$ & $\Delta R$ \\
$S_{4 a}$ & $\left(2 \Delta r_{1}-\Delta r_{2}-\Delta r_{3}\right) / \sqrt{6}$ \\
$S_{4 b}$ & $\left(\Delta r_{2}-\Delta r_{3}\right) / \sqrt{2}$ \\
$S_{5 a}$ & $\left(2 \Delta \alpha_{1}-\Delta \alpha_{2}-\Delta \alpha_{3}\right) / \sqrt{6}$ \\
$S_{5 b}$ & $\left(\Delta \alpha_{2}-\Delta \alpha_{3}\right) / \sqrt{2}$ \\
$S_{6 a}$ & $\left(2 \Delta \beta_{1}-\Delta \beta_{2}-\Delta \beta_{3}\right) / \sqrt{6}$ \\
$S_{6 b}$ & $\left(\Delta \beta_{2}-\Delta \beta_{3}\right) / \sqrt{2}$ \\
\hline
\end{tabular}

${ }^{a} r=r_{P H}, R=r_{P X}, \alpha=\angle(\mathrm{HPH})\left(101.16\right.$ for $\mathrm{OPH}_{3}, 100.23$ for $\left.\mathrm{SPH}_{3}\right), \beta=\angle(\mathrm{HPX})(116.88$ for $\mathrm{OPH}_{3}, 117.62$ for $\left.\mathrm{SPH}_{3}\right)$

${ }^{b} K=-3 \sin \beta \cos \beta / \sin \alpha$ 
Table 4: Calculated CCSD(T)/cc-pCVQZ harmonic force fields of $\mathrm{OPH}_{3}$ and $\mathrm{SPH}_{3}$ in symmetry coordinates, as defined in Table 3. Units are in $\mathrm{aJ} \AA^{-n} \mathrm{rad}^{-m}$ where $n$ is the number of stretches and $m$ the number of bendings in the definition of the force constants. For the harmonic force field $m+n=2$. Only force constants independent and non-zero by symmetry are reported. Previous theoretical values reported in ref.[5] are shown in parentheses.

\begin{tabular}{rrrr}
\hline & & $\mathrm{OPH}_{3}$ & $\mathrm{SPH}_{3}$ \\
\hline$i$ & $j$ & $f_{i j}$ & $f_{i j}$ \\
\hline 1 & 1 & $3.556(3.371)$ & $3.552(3.370)$ \\
1 & 2 & $0.047(0.041)$ & $0.085(0.074)$ \\
1 & 3 & $0.168(0.201)$ & $0.140(0.151)$ \\
2 & 2 & $0.633(0.610)$ & $0.562(0.537)$ \\
2 & 3 & $-0.173(-0.181)$ & $-0.181(-0.190)$ \\
3 & 3 & $9.879(9.423)$ & $4.569(4.210)$ \\
4 & 4 & $3.452(3.239)$ & $3.448(3.264)$ \\
4 & 5 & $-0.098(-0.079)$ & $-0.090(-0.067)$ \\
4 & 6 & $0.010(0.036)$ & $-0.018(0.003)$ \\
5 & 5 & $0.724(0.653)$ & $0.697(0.611)$ \\
5 & 6 & $-0.208(-0.205)$ & $-0.152(-0.130)$ \\
6 & 6 & $0.826(0.777)$ & $0.666(0.587)$ \\
\hline
\end{tabular}


Table 5: Calculated MP2/cc-pCVTZ cubic anharmonic force fields of $\mathrm{OPH}_{3}$ and $\mathrm{SPH}_{3}$ in symmetry coordinates, as defined in Table 3. Units are in $\mathrm{aJ}^{-n} \mathrm{rad}^{-m}$ where $n$ is the number of stretches and $m$ the number of bendings in the definition of the force constants. For the cubic force field $m+n=3$. Only force constants which are independent and non-zero by symmetry are reported

\begin{tabular}{|c|c|c|c|c|c|}
\hline & $\mathrm{OPH}_{3}$ & $\mathrm{SPH}_{3}$ & & $\mathrm{OPH}_{3}$ & $\mathrm{SPH}_{3}$ \\
\hline$i j k$ & $f_{i j k}$ & $f_{i j k}$ & $i j k$ & $f_{i j k}$ & $f_{i j k}$ \\
\hline 111 & -10.226 & -10.270 & 344 & 0.011 & 0.169 \\
\hline 112 & -0.111 & -0.115 & 345 & 0.060 & 0.052 \\
\hline 113 & -0.143 & -0.005 & 346 & -0.269 & -0.140 \\
\hline 122 & -0.168 & -0.099 & 355 & -0.156 & -0.079 \\
\hline 123 & 0.162 & 0.094 & 356 & 0.182 & 0.163 \\
\hline 133 & -0.327 & -0.332 & 366 & -0.798 & -0.791 \\
\hline 222 & 0.361 & 0.254 & 444 & -7.000 & -7.095 \\
\hline 223 & -0.368 & -0.325 & 445 & -0.191 & -0.182 \\
\hline 233 & 0.304 & 0.425 & 446 & 0.044 & 0.021 \\
\hline 333 & -62.034 & -23.705 & 455 & 0.077 & 0.081 \\
\hline 144 & -9.962 & -10.088 & 456 & 0.023 & 0.025 \\
\hline 145 & 0.089 & 0.078 & 466 & -0.102 & -0.043 \\
\hline 146 & 0.004 & 0.011 & 555 & 0.009 & 0.016 \\
\hline 155 & -0.302 & -0.306 & 556 & -0.286 & -0.234 \\
\hline 156 & 0.053 & 0.023 & 566 & 0.416 & 0.337 \\
\hline 166 & -0.193 & -0.079 & 666 & -0.779 & -0.595 \\
\hline 244 & 0.050 & 0.056 & & & \\
\hline 245 & 0.139 & 0.142 & & & \\
\hline 246 & 0.027 & -0.031 & & & \\
\hline 255 & -0.507 & -0.479 & & & \\
\hline 256 & 0.089 & 0.077 & & & \\
\hline 266 & 0.090 & 0.063 & & & \\
\hline
\end{tabular}


Table 6: Calculated MP2/cc-pCVTZ quartic anharmonic force fields of $\mathrm{OPH}_{3}$ and $\mathrm{SPH}_{3}$ in symmetry coordinates, as defined in Table 3. Units are in aJ $\AA^{-n} \mathrm{rad}^{-m}$ where $n$ is the number of stretches and $m$ the number of bendings in the definition of the force constants. For the quartic force field $m+n=4$. Only force constants independent and non-zero by symmetry are reported

\begin{tabular}{|c|c|c|c|c|c|c|c|c|}
\hline & $\mathrm{OPH}_{3}$ & $\mathrm{SPH}_{3}$ & & $\mathrm{OPH}_{3}$ & $\mathrm{SPH}_{3}$ & & $\mathrm{OPH}_{3}$ & $\mathrm{SPH}_{3}$ \\
\hline$i j k l$ & $f_{i j k l}$ & $f_{i j k l}$ & $i j k l$ & $f_{i j k l}$ & $f_{i j k l}$ & $i j k l$ & $f_{i j k l}$ & $f_{i j k l}$ \\
\hline 1111 & 24.340 & 24.554 & 2245 & -0.104 & -0.095 & 2556 & 0.227 & 0.181 \\
\hline 1112 & -0.065 & -0.161 & 2246 & 0.021 & -0.035 & 2566 & -0.317 & -0.250 \\
\hline 1113 & -0.063 & -0.114 & 2255 & 0.112 & 0.052 & 2666 & 0.316 & 0.328 \\
\hline 1122 & -0.163 & -0.145 & 2256 & 0.012 & 0.003 & 3444 & -0.247 & -0.168 \\
\hline 1123 & -0.002 & 0.077 & 2266 & 0.115 & 0.035 & 3445 & 0.068 & 0.079 \\
\hline 1133 & 0.349 & 0.232 & 2344 & -0.022 & 0.060 & 3446 & -0.060 & -0.103 \\
\hline 1222 & -0.097 & 0.016 & 2345 & -0.025 & -0.025 & 3455 & 0.025 & 0.021 \\
\hline 1223 & 0.248 & 0.097 & 2346 & -0.225 & -0.021 & 3456 & -0.058 & -0.067 \\
\hline 1233 & -0.329 & -0.238 & 2355 & 0.135 & 0.121 & 3466 & 0.341 & 0.147 \\
\hline 1333 & 1.546 & 0.789 & 2356 & -0.028 & 0.007 & 3555 & -0.088 & -0.016 \\
\hline 2222 & 1.108 & 0.670 & 2366 & -0.283 & -0.253 & 3556 & 0.266 & 0.280 \\
\hline 2223 & -0.465 & -0.409 & 3344 & 0.401 & 0.198 & 3566 & -0.309 & -0.306 \\
\hline 2233 & 0.201 & 0.316 & 3345 & 0.019 & 0.058 & 3666 & 0.797 & 0.717 \\
\hline 2333 & -0.955 & -0.292 & 3346 & 0.707 & 0.545 & 4444 & 36.972 & 37.200 \\
\hline 3333 & 332.850 & 95.180 & 3355 & 0.134 & 0.124 & 4445 & 0.219 & 0.211 \\
\hline 1144 & 24.429 & 24.587 & 3356 & -0.069 & -0.024 & 4446 & -0.042 & 0.018 \\
\hline 1145 & 0.061 & 0.069 & 3366 & 0.247 & 0.484 & 4455 & -0.269 & -0.301 \\
\hline 1146 & -0.067 & -0.023 & 1444 & 17.166 & 17.298 & 4456 & 0.074 & 0.054 \\
\hline 1155 & 0.018 & -0.010 & 1445 & 0.122 & 0.115 & 4466 & -0.258 & -0.181 \\
\hline 1156 & 0.032 & 0.030 & 1446 & 0.021 & 0.042 & 4555 & -0.253 & -0.229 \\
\hline 1166 & -0.127 & -0.094 & 1455 & 0.041 & 0.046 & 4556 & 0.154 & 0.134 \\
\hline 1244 & -0.092 & -0.155 & 1456 & -0.034 & -0.007 & 4566 & -0.122 & -0.057 \\
\hline 1245 & -0.043 & -0.020 & 1466 & -0.045 & -0.037 & 4666 & 0.227 & 0.006 \\
\hline 1246 & 0.082 & 0.027 & 1555 & -0.081 & -0.095 & 5555 & 1.376 & 1.241 \\
\hline 1255 & 0.098 & 0.078 & 1556 & 0.075 & 0.036 & 5556 & -0.789 & -0.667 \\
\hline 1256 & -0.032 & -0.042 & 1566 & -0.112 & -0.071 & 5566 & 0.804 & 0.638 \\
\hline 1266 & 0.024 & 0.081 & 1666 & 0.176 & 0.033 & 5666 & -1.324 & -1.013 \\
\hline 1344 & -0.268 & -0.178 & 2444 & -0.144 & -0.196 & 6666 & 2.224 & 1.686 \\
\hline 1345 & -0.012 & 0.004 & 2445 & 0.235 & 0.227 & $4 \mathrm{a} 4 \mathrm{a} 5 \mathrm{~b} 5 \mathrm{~b}$ & -0.733 & -0.750 \\
\hline 1346 & -0.008 & -0.115 & 2446 & 0.047 & 0.014 & $4 \mathrm{a} 4 \mathrm{a} 5 \mathrm{~b} 6 \mathrm{~b}$ & 0.076 & 0.044 \\
\hline 1355 & -0.009 & -0.054 & 2455 & 0.082 & 0.092 & $4 \mathrm{a} 4 \mathrm{a} 6 \mathrm{~b} 6 \mathrm{~b}$ & -0.079 & -0.055 \\
\hline 1356 & -0.091 & -0.032 & 2456 & -0.021 & -0.024 & $4 \mathrm{a} 5 \mathrm{a} 6 \mathrm{~b} 6 \mathrm{~b}$ & -0.048 & -0.031 \\
\hline 1366 & 0.544 & 0.237 & 2466 & -0.009 & 0.035 & $4 \mathrm{a} 6 \mathrm{a} 5 \mathrm{~b} 6 \mathrm{~b}$ & -0.037 & -0.013 \\
\hline 2244 & -0.274 & -0.234 & 2555 & -0.372 & -0.431 & $5 \mathrm{a} 5 \mathrm{a} 6 \mathrm{~b} 6 \mathrm{~b}$ & 0.553 & 0.440 \\
\hline
\end{tabular}


Table 7: Calculated spectroscopic parameters of ${ }^{16} \mathrm{OPH}_{3},{ }^{16} \mathrm{OPD}_{3},{ }^{18} \mathrm{OPH}_{3},{ }^{18} \mathrm{OPD}_{3},{ }^{32} \mathrm{SPH}_{3}$, ${ }^{32} \mathrm{SPD}_{3},{ }^{34} \mathrm{SPH}_{3}$ and ${ }^{34} \mathrm{SPD}_{3}$. All values are in $\mathrm{cm}^{-1}$. Experimental values are shown in parentheses, while most recent theoretical values are reported in square brackets

\begin{tabular}{|c|c|c|c|c|c|c|c|c|}
\hline & ${ }^{16} \mathrm{OPH}_{3}$ & ${ }^{16} \mathrm{OPD}_{3}$ & ${ }^{18} \mathrm{OPH}_{3}$ & ${ }^{18} \mathrm{OPD}_{3}$ & ${ }^{32} \mathrm{SPH}_{3}$ & ${ }^{32} \mathrm{SPD}_{3}$ & ${ }^{34} \mathrm{SPH}_{3}$ & ${ }^{34} \mathrm{SPD}_{3}$ \\
\hline$\nu_{1}$ & $\begin{array}{c}2356.4^{a} \\
(2359.0)^{d}\end{array}$ & $\begin{array}{c}1722.3^{b} \\
(1721.1)^{d}\end{array}$ & $\begin{array}{c}2340.4^{a} \\
(2367.0)^{d}\end{array}$ & $\begin{array}{c}1720.2^{b} \\
(1720.0)^{d}\end{array}$ & 2366.2 & $1716.5^{c}$ & 2366.1 & $1716.4^{c}$ \\
\hline$\nu_{2}$ & $\begin{array}{c}1262.6 \\
(1240.2)^{d}\end{array}$ & $\begin{array}{c}1236.6 \\
(1217.3)^{d}\end{array}$ & $\begin{array}{c}1235.5 \\
(1213.7)^{d}\end{array}$ & $\begin{array}{c}1193.3 \\
(1174.1)^{d}\end{array}$ & 1118.0 & 832.9 & 1118.0 & 832.3 \\
\hline$\nu_{3}$ & $\begin{array}{c}1146.7 \\
(1143.5)^{d}\end{array}$ & $\begin{array}{c}848.0 \\
(843.6)^{d}\end{array}$ & 1127.2 & $\begin{array}{c}844.5 \\
(840.5)^{d}\end{array}$ & 676.7 & 655.6 & 666.5 & 645.7 \\
\hline$\nu_{4}$ & $\begin{array}{c}2353.1 \\
(2371.5)^{d}\end{array}$ & 1715.3 & $\begin{array}{c}2357.9 \\
(2371.6)^{d}\end{array}$ & 1714.3 & 2348.5 & 1713.7 & 2348.5 & 1713.6 \\
\hline$\nu_{5}$ & $\begin{array}{c}1117.1 \\
(1114.3)^{d}\end{array}$ & 808.8 & $\begin{array}{c}1117.0 \\
(1114.3)^{d}\end{array}$ & 808.7 & 1102.2 & 794.8 & 1102.2 & 794.8 \\
\hline$\nu_{6}$ & $\begin{array}{c}846.6 \\
(853.0)^{d}\end{array}$ & $\begin{array}{c}653.8 \\
(655.9)^{d}\end{array}$ & $\begin{array}{c}842.7 \\
(849.4)^{d}\end{array}$ & $\begin{array}{c}648.9 \\
(651.3)^{d}\end{array}$ & 723.8 & 544.1 & 723.2 & 543.3 \\
\hline$\omega_{1}$ & $\begin{array}{l}2469.8 \\
{[2531]^{e}}\end{array}$ & 1768.2 & 2469.8 & 1767.9 & $\begin{array}{l}2468.3 \\
{[2506]^{f}}\end{array}$ & 1762.6 & 2468.3 & 1762.6 \\
\hline$\omega_{2}$ & $\begin{array}{l}1283.4 \\
{[1327]^{e}}\end{array}$ & 1253.5 & 1257.4 & 1209.1 & $\begin{array}{l}1143.4 \\
{[1205]^{f}}\end{array}$ & 846.6 & 1143.4 & 846.1 \\
\hline$\omega_{3}$ & $\begin{array}{l}1168.1 \\
{[1203]^{e}}\end{array}$ & 860.8 & 1146.3 & 857.2 & $\begin{array}{l}686.0 \\
{[642]^{f}}\end{array}$ & 663.9 & 675.5 & 653.7 \\
\hline$\omega_{4}$ & $\begin{array}{l}2456.7 \\
{[2505]^{e}}\end{array}$ & 1770.1 & 2456.7 & 1770.0 & $\begin{array}{l}2455.5 \\
{[2485]^{f}}\end{array}$ & 1768.8 & 2455.5 & 1768.8 \\
\hline$\omega_{5}$ & $\begin{array}{l}1145.9 \\
{[1181]^{e}}\end{array}$ & 823.5 & 1145.9 & 823.4 & $\begin{array}{l}1133.1 \\
{[1129]^{f}}\end{array}$ & 810.5 & 1133.1 & 810.5 \\
\hline$\omega_{6}$ & $\begin{array}{l}860.0 \\
{[893]^{e}}\end{array}$ & 661.7 & 856.1 & 656.7 & $\begin{array}{l}735.6 \\
{[741]^{f}}\end{array}$ & 550.8 & 735.0 & 550.0 \\
\hline$x_{11}$ & $\begin{array}{c}-14.74 \\
{[-12.02]^{g}}\end{array}$ & -7.41 & -14.75 & -7.42 & -15.01 & -7.64 & -15.01 & -7.64 \\
\hline$x_{12}$ & $\begin{array}{c}-9.70 \\
{[-16.88]^{g}}\end{array}$ & -1.21 & -26.57 & -1.31 & -1.14 & -6.86 & -1.14 & -6.92 \\
\hline$x_{13}$ & $\begin{array}{c}-6.74 \\
{[-12.90]^{g}}\end{array}$ & -7.59 & -5.75 & -7.48 & 0.76 & -0.10 & 0.75 & -0.07 \\
\hline$x_{14}$ & $\begin{array}{c}-57.51 \\
{[-47.53]^{g}}\end{array}$ & -28.95 & -57.51 & -29.00 & -60.12 & -30.63 & -60.12 & -30.63 \\
\hline$x_{15}$ & $\begin{array}{c}-7.82 \\
{[-4.25]^{g}}\end{array}$ & -3.59 & -7.82 & -3.59 & -8.57 & -4.25 & -8.57 & -4.25 \\
\hline$x_{16}$ & $\begin{array}{c}-4.69 \\
{[-4.08]^{g}}\end{array}$ & -2.65 & -4.68 & -2.62 & -3.24 & -1.63 & -3.24 & -1.63 \\
\hline$x_{22}$ & $\begin{array}{c}-2.82 \\
{[-3.75]^{g}}\end{array}$ & -5.87 & 2.16 & -5.36 & -4.60 & -0.92 & -4.60 & -0.91 \\
\hline$x_{23}$ & $\begin{array}{c}-6.15 \\
{[3.79]^{g}}\end{array}$ & -1.87 & -6.67 & -1.91 & -2.22 & -2.36 & -2.20 & -2.27 \\
\hline$x_{24}$ & $\begin{array}{c}0.38 \\
{[1.34]^{g}}\end{array}$ & -0.73 & -1.80 & -1.66 & -6.76 & -2.52 & -6.76 & -2.58 \\
\hline$x_{25}$ & $\begin{array}{c}-1.43 \\
{[0.00]^{g}}\end{array}$ & -0.62 & -1.79 & -0.60 & -4.44 & -1.93 & -4.44 & -1.95 \\
\hline
\end{tabular}




\begin{tabular}{|c|c|c|c|c|c|c|c|c|}
\hline & ${ }^{16} \mathrm{OPH}_{3}$ & ${ }^{16} \mathrm{OPD}_{3}$ & ${ }^{18} \mathrm{OPH}_{3}$ & ${ }^{18} \mathrm{OPD}_{3}$ & ${ }^{32} \mathrm{SPH}_{3}$ & $\frac{{ }^{32} \mathrm{SPD}_{3}}{3}$ & ${ }^{34} \mathrm{SPH}_{3}$ & ${ }^{34} \mathrm{SPD}_{3}$ \\
\hline$\overline{x_{26}}$ & $\begin{array}{c}-6.26 \\
{[-6.78]^{g}}\end{array}$ & -2.23 & -5.98 & -1.20 & -3.39 & -2.86 & -3.39 & -2.83 \\
\hline$x_{33}$ & $\begin{array}{c}-1.76 \\
{[-2.45]^{g}}\end{array}$ & -0.22 & -1.97 & -0.22 & -3.07 & -2.43 & -2.98 & -2.39 \\
\hline$x_{34}$ & $\begin{array}{c}-6.97 \\
{[-5.67]^{g}}\end{array}$ & -4.51 & -4.99 & -4.53 & 1.36 & 0.25 & 1.34 & 0.29 \\
\hline$x_{35}$ & $\begin{array}{c}-2.04 \\
{[-0.76]^{g}}\end{array}$ & -1.20 & -1.56 & -1.20 & -0.27 & -0.29 & -0.27 & -0.28 \\
\hline$x_{36}$ & $\begin{array}{c}-2.42 \\
{[-2.30]^{g}}\end{array}$ & -1.88 & -2.38 & -1.77 & -3.47 & -2.16 & -3.41 & -2.14 \\
\hline$x_{44}$ & $\begin{array}{c}-21.35 \\
{[-17.62]^{g}}\end{array}$ & -11.28 & -21.35 & -11.28 & -22.66 & -11.98 & -22.66 & -11.98 \\
\hline$x_{45}$ & $\begin{array}{c}-10.80 \\
{[-7.52]^{g}}\end{array}$ & -5.23 & -10.84 & -5.25 & -11.54 & -5.91 & -11.54 & -5.91 \\
\hline$x_{46}$ & $\begin{array}{c}-3.46 \\
{[-2.59]^{g}}\end{array}$ & -2.75 & -3.49 & -3.23 & -2.67 & -1.20 & -2.68 & -1.20 \\
\hline$x_{55}$ & $\begin{array}{c}-4.08 \\
{[-4.12]^{g}}\end{array}$ & -2.24 & -4.07 & -2.23 & -3.90 & -2.04 & -3.90 & -2.04 \\
\hline$x_{56}$ & $\begin{array}{c}-3.31 \\
{[-2.70]^{g}}\end{array}$ & -1.38 & -3.35 & -1.41 & -4.23 & -1.96 & -4.24 & -1.97 \\
\hline$x_{66}$ & $\begin{array}{c}-0.41 \\
{[-0.12]^{g}}\end{array}$ & -0.30 & -0.42 & -0.30 & -0.51 & -0.34 & -0.51 & -0.34 \\
\hline$g_{44}$ & $\begin{array}{c}7.60 \\
{[6.45]^{g}}\end{array}$ & 4.16 & 7.60 & 4.16 & 7.95 & 4.35 & 7.95 & 4.35 \\
\hline$g_{45}$ & $\begin{array}{c}-0.98 \\
{[-3.12]^{g}}\end{array}$ & -0.96 & -1.03 & -0.95 & -0.21 & -0.36 & -0.21 & -0.36 \\
\hline$g_{46}$ & $\begin{array}{c}0.59 \\
{[0.81]^{g}}\end{array}$ & -0.41 & 0.53 & -0.89 & 0.22 & 0.42 & 0.22 & 0.42 \\
\hline$g_{55}$ & $\begin{array}{c}3.15 \\
{[2.49]^{g}}\end{array}$ & 1.39 & 3.15 & 1.40 & 3.20 & 1.56 & 3.20 & 1.56 \\
\hline$g_{56}$ & $\begin{array}{c}-1.73 \\
{[-1.43]^{g}}\end{array}$ & -0.62 & -1.71 & -0.62 & -1.39 & -0.76 & -1.38 & -0.75 \\
\hline$g_{66}$ & $\begin{array}{c}1.30 \\
{[1.15]^{g}}\end{array}$ & 0.60 & 1.30 & 0.60 & 1.66 & 0.76 & 1.66 & 0.76 \\
\hline
\end{tabular}


Table 9: Table 7 continued

\begin{tabular}{|c|c|c|c|c|c|c|c|c|}
\hline & ${ }^{16} \mathrm{OPH}_{3}$ & ${ }^{16} \mathrm{OPD}_{3}$ & ${ }^{18} \mathrm{OPH}_{3}$ & ${ }^{18} \mathrm{OPD}_{3}$ & ${ }^{32} \mathrm{SPH}_{3}$ & ${ }^{32} \mathrm{SPD}_{3}$ & ${ }^{34} \mathrm{SPH}_{3}$ & ${ }^{{ }^{4}} \mathrm{SPD}_{3}$ \\
\hline$A_{0}$ & 3.51115 & 1.76314 & 3.51101 & 1.76311 & 3.60893 & 1.80634 & 3.60893 & 1.80634 \\
\hline$B_{0}$ & $\begin{array}{c}0.58078 \\
(0.58128953)^{h}\end{array}$ & $\begin{array}{c}0.48647 \\
(0.48699864)^{h}\end{array}$ & $\begin{array}{c}0.54186 \\
(0.54233067)^{h}\end{array}$ & 0.45568 & 0.24682 & 0.21725 & 0.23971 & 0.21099 \\
\hline$\alpha_{1}^{A} \times 10^{3}$ & $\begin{array}{c}34.548 \\
{[29.071]^{g}}\end{array}$ & 13.200 & 34.546 & 13.192 & 33.453 & 12.790 & 33.453 & 12.790 \\
\hline$\alpha_{1}^{B} \times 10^{3}$ & $\begin{array}{c}0.649 \\
{[0.469]^{g}}\end{array}$ & 3.846 & 0.576 & 2.952 & 0.075 & 0.243 & 0.070 & 0.231 \\
\hline$\alpha_{2}^{A} \times 10^{3}$ & $\begin{array}{c}-3.128 \\
{[-2.472]^{g}}\end{array}$ & 0.178 & -6.588 & 0.059 & -15.998 & -5.385 & -15.998 & -5.443 \\
\hline$\alpha_{2}^{B} \times 10^{3}$ & $\begin{array}{c}2.778^{i} \\
{[0.122]^{g}}\end{array}$ & 2.553 & $2.018^{i}$ & 2.313 & $0.288^{m}$ & $0.307^{m}$ & $0.279^{m}$ & $0.289^{m}$ \\
\hline$\alpha_{3}^{A} \times 10^{3}$ & $\begin{array}{c}-10.948 \\
{[-10.795]^{g}}\end{array}$ & -5.610 & -7.530 & -5.503 & 1.343 & -0.089 & 1.323 & -0.041 \\
\hline$\alpha_{3}^{B} \times 10^{3}$ & $\begin{array}{c}1.188^{i} \\
{[-1.062]^{g}}\end{array}$ & $0.372^{l}$ & $1.562^{i}$ & $0.325^{l}$ & 1.573 & 0.852 & 1.457 & 0.815 \\
\hline$\alpha_{4}^{A} \times 10^{3}$ & $\begin{array}{c}21.099 \\
{[16.046]^{g}}\end{array}$ & 7.657 & 21.114 & 7.659 & 20.069 & 7.286 & 20.069 & 7.286 \\
\hline$\alpha_{4}^{B} \times 10^{3}$ & $\begin{array}{c}0.665 \\
{[0.416]^{g}}\end{array}$ & -0.801 & 0.583 & -0.467 & 0.008 & 0.091 & 0.005 & 0.086 \\
\hline$\alpha_{5}^{A} \times 10^{3}$ & $\begin{array}{c}14.862 \\
{[13.570]^{g}}\end{array}$ & 2.509 & 15.040 & 2.839 & 19.885 & 6.730 & 19.887 & 6.735 \\
\hline$\alpha_{5}^{B} \times 10^{3}$ & $\begin{array}{l}-0.946^{i} \\
{[5.727]^{g}}\end{array}$ & $-1.175^{l}$ & $-0.822^{i}$ & $-1.003^{l}$ & $-0.112^{m}$ & $-0.188^{m}$ & $-0.105^{m}$ & $-0.176^{m}$ \\
\hline$\alpha_{6}^{A} \times 10^{3}$ & $\begin{array}{c}-2.331 \\
{[-5.673]^{g}}\end{array}$ & 1.689 & -2.359 & 1.391 & -9.462 & -3.369 & -9.432 & -3.357 \\
\hline$\alpha_{6}^{B} \times 10^{3}$ & $\begin{array}{c}1.562 \\
{[1.567]^{g}}\end{array}$ & 1.384 & 1.402 & 1.222 & 0.367 & 0.405 & 0.380 & 0.392 \\
\hline
\end{tabular}

${ }^{a}$ Fermi resonances of the second type between $\nu_{1}$ and $\nu_{2}+\nu_{3}$, and between $\nu_{4}$ and $\nu_{2}+\nu_{5}$, taken into account.

${ }^{b}$ Fermi resonance of the first type between $\nu_{1}$ and $2 \nu_{3}$ taken into account

${ }^{c}$ Fermi resonance of the first type between $\nu_{1}$ and $2 \nu_{2}$ taken into account

${ }^{d}$ From Ref.[18]

${ }^{e}$ MP2/6-311** calculation from ref.[7]. The scaling factor of 0.943 has been removed

${ }^{f}$ QCISD/6-311+G(d,p) calculation from Ref.[17]

${ }^{g}$ From Ref.[6]

${ }^{h}$ From Ref.[20]

${ }^{i}$ Coriolis resonances between $\nu_{2}$ and $\nu_{5}$, and between $\nu_{3}$ and $\nu_{5}$ taken into account

${ }^{l}$ Coriolis resonance between $\nu_{3}$ and $\nu_{5}$ taken into account

${ }^{m}$ Coriolis resonance between $\nu_{2}$ and $\nu_{5}$ taken into account 


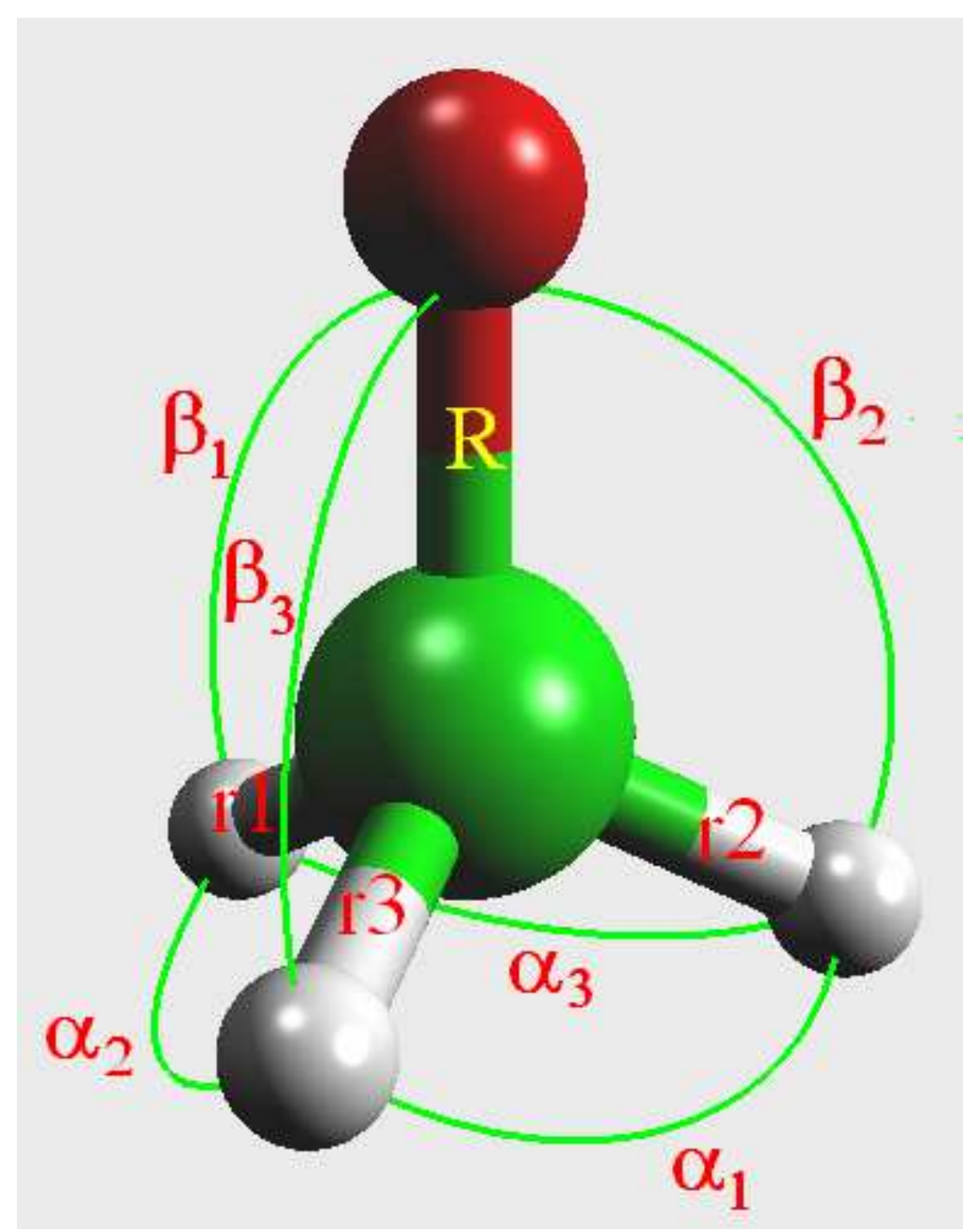

Internal coordinates used for the definition of the symmetry coordinates of $\mathrm{OPH}_{3}$ and $\mathrm{SPH}_{3}$ $102 \times 131 \mathrm{~mm}(96 \times 96 \mathrm{DPI})$ 